\title{
Pharyngeal Dysesthesia
}

National Cancer Institute

\section{Source}

National Cancer Institute. Pharyngeal Dysesthesia. NCI Thesaurus. Code C78261.

An unusual sensation in the area of pharynx. It may be the initial manifestation of seizures associated with temporal lobe epilepsy. 